\title{
The spatial and seasonal distribution of Bulinus truncatus, Bulinus forskalii and Biomphalaria pfeifferi, the intermediate host snails of schistosomiasis, in N'Djamena, Chad
}

\author{
Wendelin Moser ${ }^{1,2}$, Helena Greter ${ }^{1,2}$, Christian Schindler ${ }^{1,2}$, Fiona Allan ${ }^{3}$, Bongo N. R. \\ Ngandolo $^{4}$, Daugla D. Moto ${ }^{5}$, Jürg Utzinger ${ }^{1,2}$, Jakob Zinsstag ${ }^{1,2}$ \\ ${ }^{1}$ Department of Epidemiology and Public Health, Swiss Tropical and Public Health Institute, Basel, \\ Switzerland; ${ }^{2}$ University of Basel, Basel, Switzerland; ${ }^{3}$ Department of Life Sciences, Natural History Museum, \\ London, UK; ${ }^{4}$ Institut de Recherches en Élevage pour le Développement, N'Djamena, Chad; ${ }^{5}$ Centre de \\ Support en Santé International, N'Djamena, Chad
}

\begin{abstract}
There is a paucity of epidemiological and malacological data pertaining to schistosomiasis in Chad. In view of a recently articulated elimination agenda, a deeper understanding of the spatio-temporal distribution of schistosomiasis intermediate host snails is pivotal. We conducted cross-sectional malacological surveys during the dry season (April/May 2013) and after the short rainy season (October 2013) in N'Djamena, the capital of Chad. Snails were identified at the genus and species level using morphological keys and molecular DNA barcoding approaches. Those belonging to Bulinus and Biomphalaria were examined for cercarial shedding. Snail habitats were characterised and their predictive potential for the presence of schistosomiasis intermediate host snails explored. Seasonal patterns were studied using geographical information system and kriging in order to interpolate snail abundance data to make predictions at non-sampled locations across N'Djamena. Overall, 413 Bulinus truncatus, 369 Bulinus forskalii and 108 Biomphalaria pfeifferi snails were collected and subjected to cercarial shedding. During the dry season, one Bu. truncatus of 119 snails collected shed Schistosoma spp. cercariae $(0.84 \%)$, while $S$. mansoni was shed by one of $108 \mathrm{Bi}$. pfeifferi snails $(0.93 \%)$. None of the snails collected after the rainy season shed Schistosoma spp. cercariae. The abundance of Bu. truncatus and Bu. forskalii showed an inverse U-shape relationship with the square term of conductivity, i.e. low abundance at the lowest and highest levels of conductivity and high abundance at intermediate levels. Bi. pfeifferi showed a negative, linear association with $\mathrm{pH}$ in the dry seasons. It is planned to link these intermediate host snail data to infection data in human populations with the goal to draw a predictive risk map that can be utilised for control and elimination of schistosomiasis in N'Djamena.
\end{abstract}

Keywords: schistosomiasis, intermediate host snail, Bulinus truncatus, Bulinus forskalii, Biomphalaria pfeifferi, spatiotemporal distribution, geographical information system, kriging, Chad.

\section{Introduction}

Schistosomiasis represents the most important snailtransmitted disease with an estimated global burden of 3.3 million disability-adjusted life years (Murray et al., 2012). According to recent calculations put forth by the World Health Organization (WHO), 243 million people in 52 countries require periodic treatment with the antischistosomal drug praziquantel (WHO, 2012). WHO recently announced the goal of schistosomiasis elimination by 2025 (WHO, 2012). Transmission of schistosomiasis is entrenched into social-ecological

Corresponding author:

Jakob Zinsstag

Department of Epidemiology and Public Health

Swiss Tropical and Public Health Institute

P.O. Box, CH-4002 Basel, Switzerland

Tel: +41 61 284-8139; Fax +41 61 284-8105

E-mail: jakob.zinsstag@unibas.ch systems (Utzinger et al., 2011) with a characteristic, focal distribution of the disease due to its obligate snail intermediate host that requires human contact with contaminated freshwater bodies to close the parasite's life cycle. In Africa, Schistosoma haematobium and $S$. mansoni are the two predominant species parasitising humans and the intermediate hosts are freshwater snails of the genus Bulinus and Biomphalaria, respectively (Colley et al., 2014). S. bovis poses a considerable veterinary public health problem, since it is the key species infecting livestock (Moné et al., 1999). To assess local transmission of these parasites, an appraisal of intermediate host snail distribution, climatic suitability and human water contact patterns are essential (Brooker, 2002; Pedersen et al., 2014).

To our knowledge, there are no published malacological survey data available for Chad and very little data on human prevalence in school-aged children. A national survey carried out in 2000 revealed a coun- 
try-wide prevalence of $13.2 \%$ for S. haematobium and $1.0 \%$ for S. mansoni among school-aged children (Beasley et al., 2002). More recently, Alio et al. (2013) reported a somewhat higher prevalence of $3.4 \%$ for S. mansoni. For the peripheral neighbourhoods of the capital N'Djamena, a S. haematobium infection prevalence of $11.8 \%$ was reported in the mid-1990s (Massenet et al., 1995). For N'Djamena itself, a prevalence of $2.6 \%$ for S. haematobium (Beasley et al., 2002) and nil for S. mansoni (Alio et al., 2013) have been reported.

To deepen our understanding of the spatio-temporal distribution of snail-borne diseases, epidemiological and malacological investigations are important. Previous research has shown that microhabitat factors influence the presence and abundance of intermediate host snails (Utzinger et al., 1997a). Water temperature in lentic environments and current velocity in lotic environments are among the most important abiotic factors identified to date (Appleton, 1978; Utzinger et al., 1997b). Several abiotic water factors are affecting snail habitats, and thus influence snail presence and abundance. Conductivity, a measure of the total solids and dissolved ions in the water, and $\mathrm{pH}$ have been suggested to be of importance for the distribution of Bulinus and Biomphalaria (Kader, 2001; Kariuki et al., 2004; Kazibwe et al., 2006), while turbidity and oxygen are of lesser relevance (Abdel Malek, 1958; Appleton, 1978). Additionally, biotic factors are associated with the presence or absence of intermediate host snails, most importantly different species of aquatic vegetation (Boelee and Laamrani, 2004; Owojori et al., 2006; Chingwena et al., 2011). Yet, there is a paucity of knowledge about limiting factors for snail habitat preferences, and hence, malacological studies are required to fill this gap (Adema et al., 2012).

For predictive risk mapping of schistosomiasis and intermediate host snail distribution, geographical information system (GIS) and remotely sensed satellite data have been shown as useful tools at different spatial and temporal scales (Brooker, 2002; Simoonga et al., 2009; Schur et al., 2011; Standley et al., 2012; Stensgaard et al., 2013). However, the relatively coarse spatial resolutions (e.g. $1 \times 1 \mathrm{~km}$ ) of freely available data do not allow for small-scale prediction with covariates.

The purpose of this study was to determine the spatio-temporal distribution of schistosomiasis intermediate host snails in N'Djamena, Chad and to assess for Schistosoma infection in snails. We pursued an integrated eco-geographical approach, consisting of mala- cological surveys, freshwater habitat characterisation, GIS and kriging. Surveys were conducted both in the dry season and after the short rainy season to generate spatially explicit risk maps for schistosomiasis transmissions. Our findings are of contemporary relevance, particularly in view of defining a schistosomiasis elimination agenda, as expressed by Rollinson et al. (2013).

\section{Material and methods}

\section{Study area and water-contact activities}

N'Djamena (geographical coordinates $12^{\circ} 6^{\prime} 47^{\prime \prime} \mathrm{N}$ latitude and $15^{\circ} 2^{\prime} 57^{\prime \prime}$ E longitude) is the capital of Chad. It is administratively divided into 10 districts with a total population estimated at 1 million in 2009 (GeoHive, 2014). In the south-west, the Chari River and the Logone River form a natural border to Cameroon. The climate of N'Djamena is semi-arid with a short rainy season from June to September and a long dry season with peak temperatures recorded in April, when the monthly average is above $40^{\circ} \mathrm{C}$ (measured at the N'Djamena airport weather station).

The water levels of rivers and ponds within the city are highly variable. During the rainy season, depending on the amount of rainfall, rivers might flood adjacent dwellings. After the rainy season in 2012, the Walia district, situated between the Chari and Logone rivers in the south-eastern part of the city, experienced serious flooding. During the dry season, the Chari River bed consists of hundreds of puddles and ponds of varying sizes. There is extensive vegetation (grass, bushes, trees and aquatic plants), which is intensively used by humans and animals. Common activities include cloth washing and bathing, mud brick production, grazing of herds of cattle, sheep and goats, and agricultural activities (e.g. urban farming). Within the city limits, the ponds nearly disappear towards the end of the dry season. The lack of sanitation, keeps the river bed contaminated with human and animal excreta. Only the Ndjaré canal, which divides N'Djamena from east to west, still contains surface water during that time.

\section{Design}

The sampling was conducted during the dry season, from mid-April to mid-May 2013 and after the rainy season in October 2013. The surveyed area in N'Djamena extends over a surface of 11 x $16 \mathrm{~km}$ (Fig. 1). A systematic sampling approach was 
employed to define, in advance, the sampling points of three different water systems in N'Djamena: the Chari River, the Ndjaré canal and selected city ponds. Pre-defined sampling points were determined using Google Earth version 7.1.2.2041 (Google Inc.; Mountain View, USA) after which coordinates (in WGS 1984, latitude and longitude) were transferred onto a global positioning system (GPS) device (Garmin eTrex 10; Olathe, USA) to facilitate geolocation in the field. Restricted areas and private dwellings were subsequently excluded.

For the sampling along the river, a random starting point was chosen on the northern river shore. After every $\mathrm{km}$, a transect line (see Fig. 1, red line) was placed perpendicular to the previous and next point across the river. All water points within $100 \mathrm{~m}$ to the left and right from this transect line were used for sampling and defined as a transect (see Fig. 1, orange band). The canal sampling points were chosen every $500 \mathrm{~m}$ and collections were carried out either at the right or at the left bank within a buffer of $50 \mathrm{~m}$ of the pre-defined point. The larger ponds, which contained water during the dry and rainy seasons, were sampled once on the western and once on the eastern bank. During the second sampling shortly after the rainy season (October), the sampling sites were chosen as close as possible to the previous sampling sites. Due to the different water levels between seasons, the second sampling sites were not always at exactly the same locations, but as close as possible to the sampling sites during the dry season (April/May).

\section{Sampling}

Snail surveys were carried out by the first author, adhering to standard protocols. In brief, snails were collected for $15 \mathrm{~min}$ at each site either with a scoop (Mandahl-Barth, 1962) or with forceps to remove them from aquatic plants. All collected snails were transferred to the laboratory of the "Institut de Recherches en Élevage pour le Développement" in N'Djamena, in labelled Petri-dishes on wet cotton. In the laboratory snail were identified a genus or species level, subjected to cercarial shedding and shell sizes were measured (in mm) using callipers. Snails of the genera Bulinus and Biomphalaria were identified using a morphological key (Mandahl-Barth, 1962). All snails were fixed in $70 \%$ ethanol and transferred to the Swiss Tropical and Public Health Institute (Swiss $\mathrm{TPH})$ in Basel, Switzerland. Representative specimens

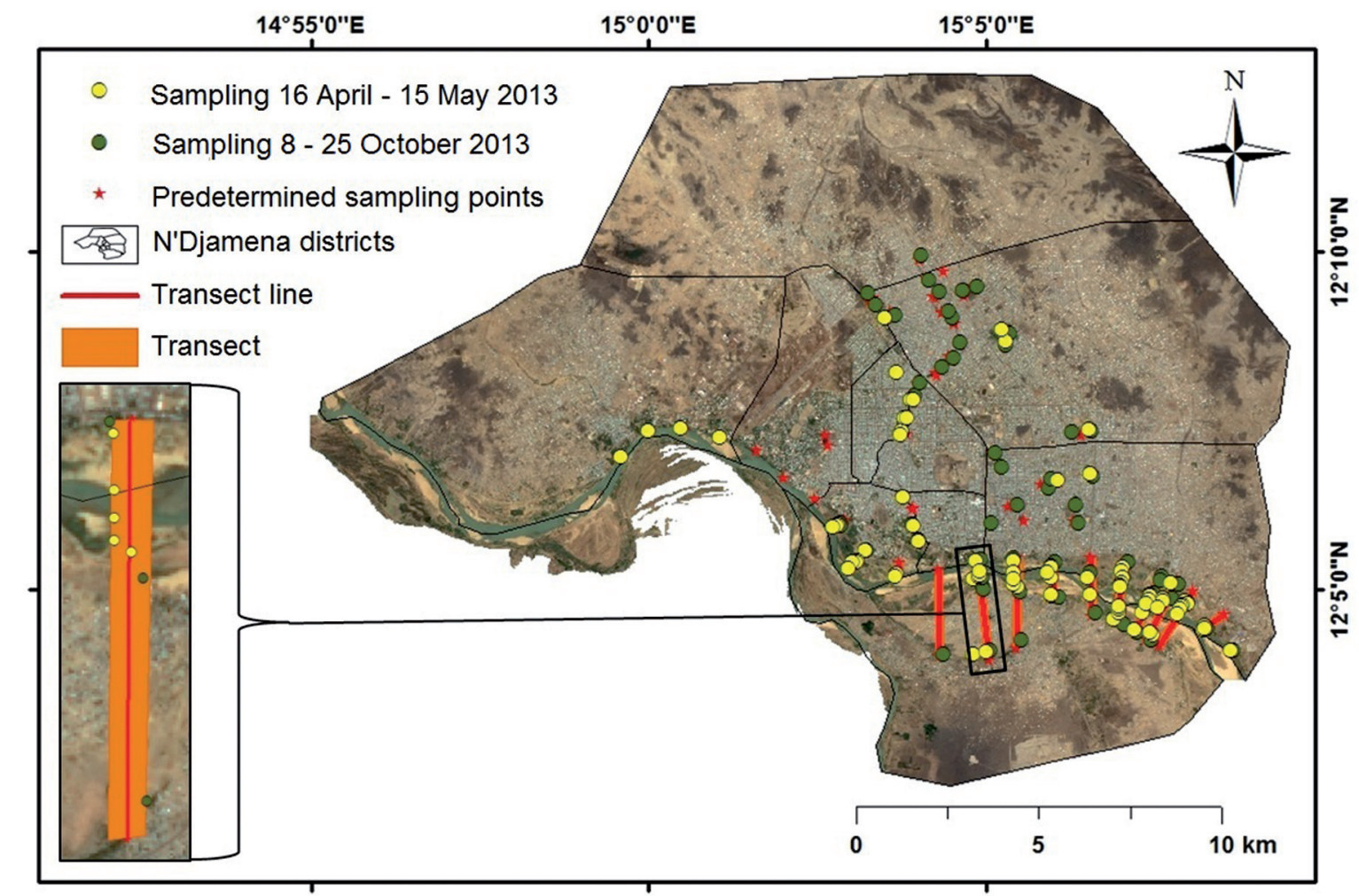

Fig. 1. Study design and sampling sites at the end of the dry season (April/May 2013) and after the rainy season (October 2013) in N'Djamena, Chad. 
of the genera Bulinus and Biomphalaria were sent to the Natural History Museum (NHM) in London, UK for species identification by molecular characterisation. Total genomic DNA was isolated using the "DNeasy Blood and Tissue kit" (http://www.qiagen.com/) and eluted into $200 \mu \mathrm{l}$ purified water. A polymerase chain reaction (PCR) amplification of a partial cytochrome oxidase 1 ( $\operatorname{cox} 1)$ sequence was performed using primers LCO1490 (5'GGTCAACAAATCATAAAG ATATTGG3' forward) and HCO2198 ( 5'TAAACTTCAGGGTGACCAAAAAATCA3' reverse) (Folmer et al., 1994). PCR investigations and sequencing conditions were chosen as outlined by Kane et al. (2008). The electropherograms produced were checked and cox 1 sequences edited using Geneious, version 5.6 (http://www.geneious.com/). Sequences were checked by performing BLAST searches via the National Center for Biotechnology Information against GenBank and EMBL sequence databases; and aligned with reference material (Kane et al., 2008) using Geneious version 5.6.

At around 11 a.m., living, sampled snails were placed individually in 24-well plates filled with tap water and placed under artificial light to induce shedding. After 3-4 hours (Steinauer et al., 2008), each well was examined for the presence of cercariae under a stereo microscope (magnification: 12-25 x). All cercariae found were transferred onto a slide, inspected with a compound microscope (magnification: $4 \mathrm{x} / 0.10$ and $10 \mathrm{x} / 0.25)$ and identified by the morphological characteristics using the identification key of Frandsen and Christensen (1984).

\section{Environmental data}

The following water parameters were recorded using a portable multimeter $\left(\mathrm{Hach}^{\circledR}, \mathrm{HQ} 40 \mathrm{D}\right.$, Loveland, USA) for temperature $\left({ }^{\circ} \mathrm{C}\right), \mathrm{pH}$, conductivity $(\mu \mathrm{S} / \mathrm{cm})$ and oxygen $(\mathrm{mg} / \mathrm{l}$; data only available for the end of the rainy season). The turbidity (FNU) was measured with a portable turbidimeter $\left(\mathrm{Hach}^{\circledR}, 2100 \mathrm{P}\right.$ ISo). Several different habitat characteristics were noted, including the type of habitat (flowing river, river bed puddle, canal and city pond), vegetation (aquatic, subaquatic and detritus) and surrounding growth (trees, bushes and grass).

\section{Spatial and statistical analysis}

Two satellite images, one taken durig the dry season (23 May 2013) and the other taken after the short rainy season (30 October 2013), were acquired from the Landsat 8 for the Universal Transverse Mercator (UTM) zone $33 \mathrm{~N}$ (path 184 row 52), which includes N'Djamena. The eight bands of the satellite images were processed and pan sharpened to a resolution of $15 \times 15 \mathrm{~m}$. Shapefiles of the extent of water surface were created using ArcGIS version 10.1 (ESRI; Redlands, USA). As no images from the Landsat 7 and 8 were available for the maximum water surface extent, available Google Earth images spanning a 3year period ending in 2013 were compared. The image obtained on 23 October 2012 was chosen. Indicator kriging using ArcGIS was performed for three snail species (Bu.truncatus, Bu. forskalii and Bi.pfeifferi), using punctual sample data (Guimarães et al., 2009) to interpolate and estimate snail abundance at non-sampled areas of N'Djamena.

Comparisons were stratified by type of habitat (river versus city). The Wilcoxon rank-sum test was used to compare the mean snail shell sizes and additionally the mean of the water parameters at sites with presence of $B u$. truncatus between seasons. The snail species compositions of the habitats were assessed by Fisher's exact test.

Whether the presence of snails showed a habitat shift between seasons was assessed using exact logistic regression with habitat (city versus river), season (dry versus end of rainy season) and interaction between habitat and season taken as a factor. Ordinary logistic regression was used to assess the association of water parameters with the presence and absence of snail species. The models were adjusted for habitat types (city versus river) and season. For each quantitative predictor variable, we assessed whether linearity could be assumed for its influence on the logit of snail abundance. This was done by categorising the variable or by adding a square term. Among the different parameterisations, the one with the lowest Akaike information criterion (AIC) was chosen. Due to the small number of observations, a maximum of two parameters were kept and parameters which did not improve the model in terms of AIC were removed. All statistical analyses were done with STATA version 12.1 (Stata Corporation; College Station, USA).

\section{Ethical considerations}

The study protocol was approved by the ethics committees of Basel (EKBB; reference no. 64/13) and Chad (reference no. 343/MSP/SE/DGAS/2013). For the transfer of snails from Chad to Switzerland, a material transfer agreement was obtained from the "Institut de Recherches en Élevage pour le Développement" (reference no. 626/PR/PM/MDPPA/SG/IRED/2013). 


\section{Results}

\section{Snail presence, abundance and infection}

The following snail species were identified morphologically and confirmed by molecular characterisation Bu.truncatus (Audoin, 1827), Bu.forskalii (Ehrenberg, 1831) and Bi.pfeifferi (Krauss, 1848). Additionally another snail of medical importance Lymnaea natalensis (Krauss, 1848) - was identified morphologically only. While the presence and abundance of Bulinus and Biomphalaria were estimated, with regard to L. natalensis, only the presence/absence at each sample site was noted. Overall, 144 sites (Fig. 1) were sampled for snails and characterised physicomorphologically and chemically; 83 during the dry season and the remaining 61 after the rainy season. In 51 of the sampled sites, a total of 892 snails were collected: 413 (46.3\%) Bu.truncatus, 371 (41.6\%) Bu. forskalii and 108 (12.1\%) Bi.pfeifferi (Table 1). The species composition was dependent on the season. Whilst Bu.truncatus was present in high numbers during both rainy and dry seasons, Bu.forskalii and Bi.pfeifferi showed seasonal preferences. During the dry season, Bu.truncatus snails were found only in ponds at the riverbed at 14 collection sites with a mean number of 8.3 snails ( $\mathrm{n}=119$, standard deviation (SD) 10.9 , range $1-40)$. At the end of the rainy season this species was found at 10 sites in the city $(\mathrm{n}=282)$ and three at the river $(\mathrm{n}=12)$ with a mean number of 22.6 snails (SD 23.8, range 1-61). We found a high seasonal variation of mean snail numbers $(P=0.074)$. In AprilMay, Bu. forskalii was lowest in number with only two specimens, collected at different sites along the river. However, after the rains ceased in October, $\mathrm{Bu}$. forskalii was the predominant species with an average of 18.9 snails (SD 16.8, range 1-52) collected per site within the city. The opposite was observed for Bi. pfeifferi, as this species was only collected in the dry season with a mean of 10.7 snails (SD 16.6, range 159) at 11 sampling sites along the river.

All Bu.truncatus were examined for cercarial shedding (Table 1). One of the 119 snails collected during the dry season shed Schistosoma spp. cercariae (infection rate $0.84 \%$; 95\% confidence interval (CI) 0.02 $4.6 \%$ ), whereas $S$. mansoni was present in one of the 108 Bi.pfeifferi specimens analysed (infection rate $0.93 \%$; 95\% CI 0.02-5.0\%). No Schistosoma infections were found in snails during the collection at the end of the rainy season. However, a larger number of snails in both seasons were infected with several other cercariae species, the majority amphistome cercariae.

\section{Structure and composition of snail populations}

The recorded shell sizes of the intermediate host snails showed seasonal differences. As shown in Table 1 , the average shell size of Bu.truncatus collected in April/May was highly significantly larger than that of the snails collected in October $(7.4 \mathrm{~mm}$ versus $6.4 \mathrm{~mm}$, $\mathrm{P}<0.001$ ).

Most of the snail populations at the sample sites during the dry season at the Chari River and at the end of the rainy season within the city were composed of several species. The results of the Fisher's exact test, including all sampled sites of the dry season, showed that the presence of $B u$. truncatus was positively associated with the presence Bi.pfeifferi $(\mathrm{P}<0.001)$ and L. natalensis $(\mathrm{P}<0.001)$ at the river. The presence of Bi.pfeifferi showed a significant positive association with $L$. natalensis $(\mathrm{P}<0.001)$ in the dry season. At the end of the rainy season, the abundance of $B u$. forskalii was significantly associated with Bu.truncatus $(\mathrm{P}<0.001)$.

Table 1. Abundance and size of Bulinus truncatus, Bulinus forskalii and Biomphalaria pfeifferi, collected in the dry season (April/May 2013) and at the end of the rainy season (October 2013) in N'Djamena, Chad.

\begin{tabular}{|c|c|c|c|c|c|c|}
\hline \multirow[t]{2}{*}{ Season } & \multirow[t]{2}{*}{ Species } & \multicolumn{2}{|c|}{ Abundance } & \multicolumn{3}{|c|}{ Size } \\
\hline & & No. (\%) & Infected snails $(\%)$ & Mean (mm) & Standard deviation & Range (mm) \\
\hline \multirow[t]{2}{*}{ Dry } & $\begin{array}{l}\text { Bu. truncatus } s^{1,2} \\
\text { Bu. forskalii }\end{array}$ & $\begin{array}{c}119(52.0) \\
2(0.9)\end{array}$ & $\begin{array}{c}1(0.84) \\
0\end{array}$ & $7.4^{3}$ & 2.5 & $3.0-12.5$ \\
\hline & Bi. pfeifferi ${ }^{2,4}$ & $108(47.1)$ & $1(0.93)$ & 3.3 & 0.5 & $2.0-4.5$ \\
\hline \multirow[t]{2}{*}{ Rainy } & Bu. truncatus $^{1}$ & $294(44.3)$ & 0 & $6.4^{3}$ & 1.3 & $3.0-11.5$ \\
\hline & Bu. forskalii ${ }^{4}$ & $369(55.7)$ & 0 & 6.7 & 1.9 & $3.5-15.0$ \\
\hline
\end{tabular}

\footnotetext{
${ }^{1}$ Significant seasonal difference in the spatial distribution city versus river $(\mathrm{P}=0.01$ for interaction term between habitat and season in an exact logistic regression model); ${ }^{2}$ Significant positive association with abundance of $L$. natalensis (Fisher's exact test $\mathrm{P}<0.001$ ); ${ }^{3}$ Significant difference in mean between the dry and rainy season (Wilcoxon sum-rank test, $\mathrm{P}<0.001$ ); ${ }^{4}$ Significant positive association with abundance of $B u$. truncatus (Fisher's exact test $\mathrm{P}<0.01$ ).
} 
Table 2. Water parameters for habitats where schistosomiasis intermediate host snails were present.

\begin{tabular}{|c|c|c|c|c|c|c|c|c|c|c|c|c|c|}
\hline \multirow[t]{2}{*}{ Season } & \multirow[t]{2}{*}{ Species } & \multicolumn{3}{|c|}{ Temperature $\left({ }^{\circ} \mathrm{C}\right)$} & \multicolumn{3}{|c|}{$\mathrm{pH}$} & \multicolumn{3}{|c|}{ Conductivity $(\mu \mathrm{S} / \mathrm{cm})$} & \multicolumn{3}{|c|}{ Turbidity (FNU) } \\
\hline & & Mean & SD & Range & Mean & SD & Range & Mean & SD & Range & Mean & SD & Range \\
\hline \multirow[t]{2}{*}{ Dry } & Bu. truncatus & 31.8 & 3.2 & $28.5-37.9$ & $6.3^{1}$ & 0.6 & $5.6-7.6$ & $217^{2}$ & 96 & $86-361$ & $219^{3}$ & 273 & $21-1,000$ \\
\hline & Bi. pfeifferi & 30.7 & 1.7 & $28.1-34.1$ & 6.1 & 0.5 & $5.7-7.6$ & 228 & 138 & $86-525$ & 170 & 289 & $21-1,000$ \\
\hline \multirow[t]{2}{*}{ Rainy } & Bu. tru & 29.2 & 3.0 & $25.4-$ & $8.3^{1}$ & 0.9 & 7.1 & $271^{2}$ & 13 & 52 & $56^{3}$ & 43 & $8-152$ \\
\hline & Bu. forskalii & 28.2 & 2.7 & $24.7-33.6$ & 8.3 & 0.7 & $6.9-9.8$ & 453 & 207 & $52-832$ & 80 & 60 & $8-250$ \\
\hline
\end{tabular}

Observations: $B u$. truncatus dry $(\mathrm{n}=14), B i$. pfeifferi dry $(\mathrm{n}=11), B u$. truncatus rainy $(\mathrm{n}=13), B u$. forskalii rainy $(\mathrm{n}=20)$; ${ }^{1}$ Significant difference in mean between dry and rainy season (Wilcoxon rank-sum test, $\mathrm{P}<0.001$ ) but not significant after stratification by habitat (city versus river); ${ }^{2}$ Significant difference in mean between dry and rainy season after stratification by habitat (city versus river) $\left(\mathrm{P}=0.02\right.$, after Bonferroni correction); ${ }^{3}$ Marginally significant difference in mean between dry and rainy season (Wilcoxon rank-sum test $\mathrm{P}=0.065$ ) but not significant after stratification by habitat (city versus river).

\section{Water data}

Specific water parameters for the presence of each snail species were recorded (Table 2). For habitats containing $\mathrm{Bu}$. truncatus, the $\mathrm{pH}$ changed from April/May $($ mean $=6.3)$ to October $($ mean $=8.3)$ and this increase showed a highly statistically significant difference $(\mathrm{P}<0.001)$. We found a borderline significant difference in turbidity (218.8 versus $55.9 \mathrm{FNU}$ ) according to season (Wilcoxon rank-sum, $\mathrm{P}=0.065$ ). The $\mathrm{pH}$ and turbidity showed no significant difference between seasons after stratification by habitat (city versus river), however the conductivity was significantly different between the seasons $(\mathrm{P}=0.020$ after Bonferroni correction).

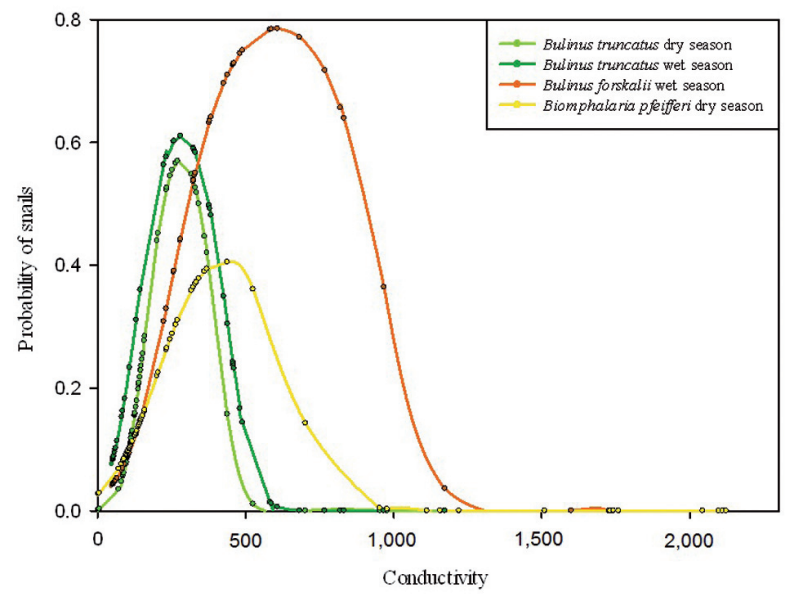

Fig. 2. Logistic regression models for conductivity and the presence of snails.

\section{Logistic regression models}

None of the models displayed a cluster effect (habitat: puddles, river, canal and city ponds). The interaction term of the exact logistic regression showed a significant difference of habitats (city versus river) between seasons $(P=0.01)$. In the model for both seasons, we found an inverse U-shape between the presence of Bu.truncatus and conductivity $(\mathrm{P}=0.001)$. The model for $\mathrm{Bu}$. forskalii included a quadratic term of conductivity $(\mathrm{P}=0.030)$ and the respective functional form showed an inverse U-shape. Regarding the abundance of $B i$.pfeifferi in its exclusive habitat (ponds and puddles) along the river, conductivity was not a significant predictor, while $\mathrm{pH}$ showed a significant negative association $(\mathrm{P}<0.001)$.

\section{Spatial distribution of intermediate host snails}

The spatial distribution and spread of the aquatic snails in N'Djamena depends on the presence of water and therefore on the surface extent of the water bodies. During the dry season, the Chari River carries little water, and hence the sandy river bed partly dries up. The remaining puddles and ponds contain aquatic and subaquatic vegetation, creating suitable habitats for aquatic snails. Bu.truncatus snails were present at 12 out of 43 sites and Bi. pfeifferi snails were found in 10 out of 43 sites, in contrast to the flowing river where these snail species were found only at two sites and one site, respectively.

The water bodies in the city (ponds and canal) were either almost or fully dried out during the dry season and no snails were found. After the rainy season, the ponds and canal carried more water and the total water surface increased, thus providing potentially 
suitable habitats for aquatic snails. At five out of 14 sampling sites along the canal, Bu. forskalii snails were found. Bu.forskalii and Bu.truncatus were also detected at 14 out of 18 sampling sites at city ponds. There was a significant shift of Bu. truncatus from the river (puddles and flowing river habitats) into the city (canal and pond habitat) according to season $(\mathrm{P}=0.011)$.

The results of the interpolated abundance of the snails, obtained from indicator kriging (Fig. 3), showed a possible shift of the snail "hotspots" from the river to the city depending on the season. The kriged abundance maps displayed a high abundance for Bu.truncatus at the river during the dry season and in city ponds and the canal at the end of the rainy season. Bi.pfeifferi was only present along the river. $B u$. forskalii was present in city water bodies after the rainy season, but this species was rarely found at the river sites. The boundary of the highest water extent in the 3 years preceding this study (23 October 2012) showed the potential habitat extent for aquatic snails. Because snail microhabitat preferences are restricted to shallow water with a depth less than $50 \mathrm{~cm}$ and a distance to the shoreline of $40 \mathrm{~cm}$ (Utzinger and
Tanner, 2000; Boelee and Laamrani, 2004), the area between the boundaries of the highest water extent and the actual water surface extent shows the potential maximum spread of the snails within N'Djamena.

\section{Discussion}

During the dry season the residual puddles and ponds along the Chari River in N'Djamena provide suitable habitats for Bi. pfeifferi (Utzinger and Tanner, 2000), as well as for the two Bulinus species. However, most of the ponds in the city were dry in the April/May survey, and hence no living snails were found. Importantly though, snails are able to aestivate at the bottom of dried ponds at a depth up to $3 \mathrm{~cm}$ in the soil (Betterton et al., 1988), and can rapidly repopulate when the rains refill the ponds. Hence, when conditions become suitable, snail populations can rapidly restore, as has been observed for Bu.truncatus and $B u$. forskalii in the current study. After the short rainy season the surfaces of the Chari River reaches the highest level with fastest water velocity, which is a limiting factor for Bi. pfeifferi abundance (Utzinger et al., 1997b).
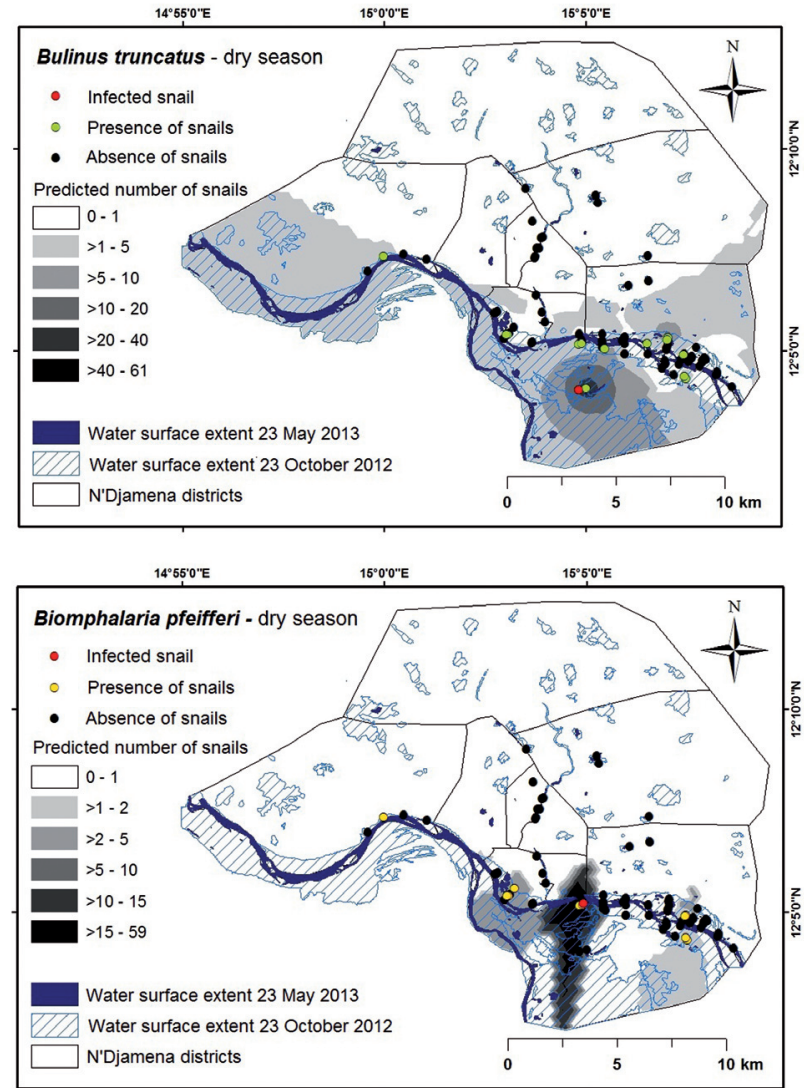
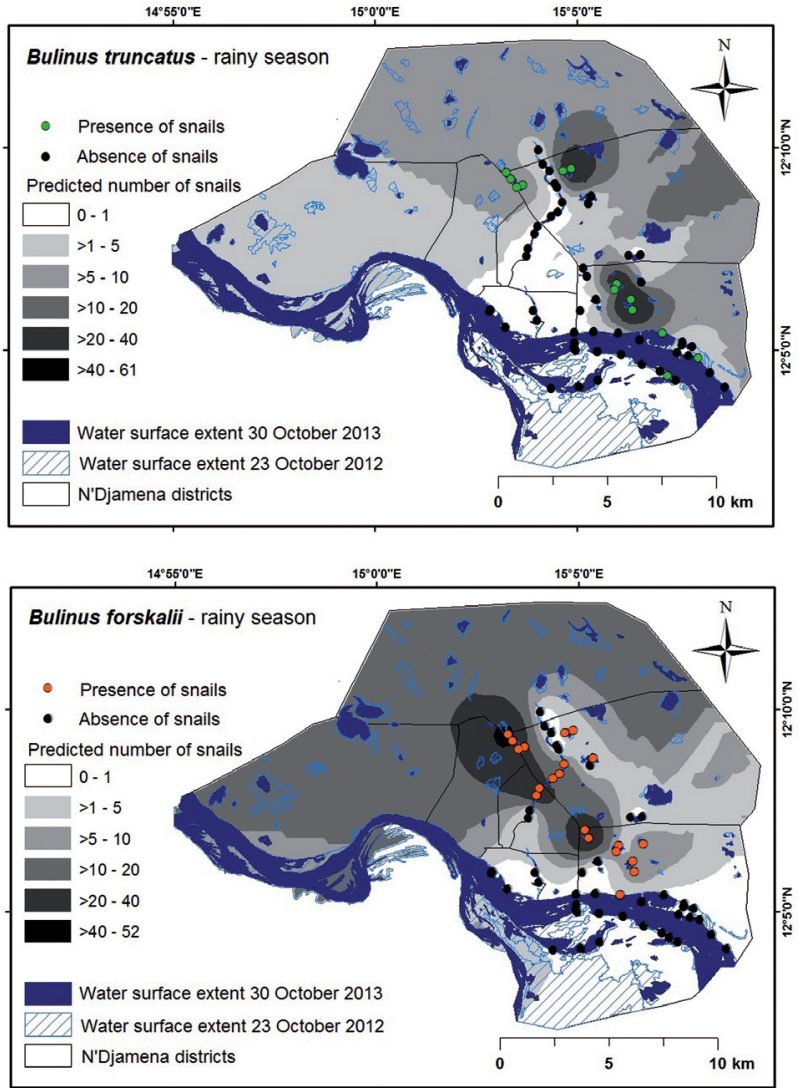

Fig. 3. The estimated snail abundance for N'Djamena, Chad. 
Snail population composition varied by seasons. For instance, Bu.truncatus was found in both seasons, with a higher abundance at the end of the rainy season within the city. Our results are in line with findings from Nigeria (Owojori et al., 2006), but are in contrast with observations made by Ngonseau et al. (1992) in Cameroon, where peak numbers of $B u$.truncatus snails were reported at the end of the dry season. Studies conducted in Nigeria (Owojori et al., 2006; Ayanda, 2009) showed the same pattern for Bi.pfeifferi but a different pattern for Bu.forskalii, where the peak was observed in the dry season.

Only single specimens of Bu. truncatus and Bi. pfeifferi were found to shed Schistosoma cercariae, thus demonstrating low active transmission of schistosomiasis in N'Djamena. However, given the relatively small numbers of snails collected (slightly more than 100 specimens in the dry season), the confidence interval around the point estimates are quite large. Additional studies are needed and efforts should be made to collect larger numbers of snails to obtain more precise infection information with smaller accompanying confidence intervals. Despite this shortcoming, it is interesting to compare our results with findings by other researchers. Ngonseu et al. (1992) in the SudanoSahelian zone of Cameroon, reported low infection rates of $S$. haematobium in Bu.truncatus snails $(1.2 \%)$, whereas Labbo et al. (2003) in Niamey, Niger found a several-fold higher infection rate $(5 \%)$. In our study, the infection rate of Bi.pfeifferi was more than a magnitude lower compared to previous studies in urban $(9.7 \%$ ) (Njiokou et al., 2004) and rural parts of Cameroon (21.3\%) (Ayanda, 2009). In our study, none of the 371 collected Bu.forskalii snails shed Schistosoma spp., whilst previous investigations carried out in Cameroon and Niger revealed, very low infection rates of $0.08 \%$ and $0.05 \%$, respectively (Ngonseu et al., 1992; Labbo et al., 2007).

The number of Bu.truncatus snails correlated with Bi. pfeifferi and L. natalensis during the dry season, and with $\mathrm{Bu}$. forskalii after the end of the rainy season. In a previous study conducted in Nigeria, Owojori et al. (2006) found an association between Bu.truncatus and Bi.pfeifferi. L. natalensis acts as intermediate hosts of the livestock (and human) trematodes Fasciola (Brown, 1994) and was found to be associated with the presence of Bi.pfeifferi and $B u$. truncatus in N'Djamena.

The models across the seasons for Bu.truncatus and for Bu. forskalii with the lowest AIC included a quadratic term of conductivity with a negative coefficient, describing an inverse U-shape relation. Prior studies also suggest an association of the presence of $B u$.truncatus and Bu.forskalii with conductivity (Kader, 2001; Kariuki et al., 2004). The model with the lowest AIC for Bi.pfeifferi included a significant negative effect of $\mathrm{pH}$, confirming previous observations by Kazibwe et al. (2006). Our results are based on relatively small sample sizes. Hence, only two parameters were included in each model, which leaves room for confounding effects. Conductivity might have a specific influence on the presence of the snails and should be assessed in future studies to specify the effect of conductivity. The abundance of snails is not depending on a single environmental factor, but is rather the result of a complex interactions of multiple habitat factors (Utzinger et al., 1997a). Moreover, the air temperature has an impact on water temperature and therefore on the water parameters and depends on season, size of water body and daily change of the air temperature. The measurement of the water temperature was performed in parallel with the snail collection in the morning (between 7 a.m. and 11 a.m.). Given our limited financial and human resources, we were unable to measure daily variation. Further investigations studying diurnal changes of water temperature are warranted to adjust for water temperature and water parameters according to the exact sampling time.

GIS-based modelling to determine environmental requirements of intermediate host snails, coupled with parasitological data and advanced Bayesian geostatistical modelling have been utilised for predictive risk profiling of schistosomiasis (Kristensen et al., 2001; Brooker, 2002; Standley et al., 2012; Stensgaard et al., 2013). Such prediction maps can likely be enhanced by incorporating significant environmental covariates and aquatic factors using Bayesian inference. Since environmental data at a suitably high spatial resolution were not freely available, the snail abundance data were instead kriged to create a predictive map of the abundance of the different schistosomiasis intermediate host snails in N'Djamena. To further improve modelling attempts, environmental and aquatic factors (e.g. habitat types, ground substrate, turbulence, water velocity and water chemistry) should be considered as covariates. Our preliminary kriging maps, however, highlight the abundance of Bu.truncatus and Bi. pfeifferi along the Chari River, the main abundance and transmission "hotspots" during the dry season and showed reasonable agreement with a previous report (Labbo et al., 2003). At the end of the rainy season, the main abundance for Bu.truncatus and $B u$. forskalii shifted towards the city, where no infected snails were found. 
The kriged maps provide an estimate of the real seasonal distribution and could provide an "auxiliary" tool (Guimarães et al., 2009) for the planning of prevention, control, surveillance and elimination of schistosomiasis. The distribution of the intermediate hosts snail should be reflected by infection within the human population. Future studies should investigate the prevalence of Schistosoma spp. in school-aged children and other high risk groups in N'Djamena. Finally, predictive risk maps of N'Djamena, using data of human schistosomiasis and snail abundance, should be drawn up for planning and implementing strategies to eliminate schistosomiasis in this major town in the Sahelian belt of Central Africa.

\section{Acknowledgements}

We thank Prof. Eliézer K. N’Goran and Dr. Yves-Nathan T. Tian-Bi from the Université Félix Houphouët-Boigny in Abidjan for malacological training. Special thanks are addressed to Prof. Idriss Alfaroukh, Director of the "Institut de Recherches en Élevage pour le Développement”. For the support with ArcGIS, we are indebted to Dr. Danielle Vienneau and Mr. Sirak Z. Gebreab from the Swiss Tropical and Public Health Institute. Thanks are also addressed to Prof. Thomas K. Kristensen from the University of Copenhagen for help with snail identification. This study recived financial support by the Swiss National Science Foundation (grant no. 141246).

\section{References}

Abdel Malek E, 1958. Factors conditioning the habitat of bilharziasis intermediate hosts of the family Planorbidae. Bull World Health Organ 18, 785-818.

Adema CM, Bayne CJ, Bridger JM, Knight M, Loker ES, Yoshino TP, Zhang SM, 2012. Will all scientists working on snails and the diseases they transmit please stand up? PLoS Negl Trop Dis 6, e1835.

Alio HM, Tidjani A, Otchom BB, Tidjani MT, Felix BBC, 2013. An epidemiological assessment of the infectious forms of intestinal helminths in school children from Chad. J Biol Life Sci 4, 341-361.

Appleton CC, 1978. Review of literature on abiotic factors influencing the distribution and life cycles of bilharziasis intermediate host snails. Malacol Rev 11, 1-25.

Ayanda OI, 2009. Prevalence of snail vectors of schistosomiasis and their infection rates in two localities within Ahmadu Bello University (A.B.U.) Campus, Zaria, Kaduna State, Nigeria. J Cell Anim Biol 3, 58-61.

Beasley M, Brooker S, Ndinaromtan M, Madjiouroum EM, Baboguel M, Djenguinabe E, Bundy DAP, 2002. First nationwide survey of the health of schoolchildren in Chad. Trop Med
Int Health 7, 625-630.

Betterton C, Ndifon GT, Tan RM, 1988. Schistosomiasis in Kano state, Nigeria. II. Field studies on aestivation in Bulinus rohlfsi (Clessin) and B. globosus (Morelet) and their susceptibility to local strains of Schistosoma haematobium (Bilharz). Ann Trop Med Parasitol 82, 571-579.

Boelee E, Laamrani H, 2004. Environmental control of schistosomiasis through community participation in a Moroccan oasis. Trop Med Int Health 9, 997-1004.

Brooker S, 2002. Schistosomes, snails and satellites. Acta Trop 82, 207-214.

Brown DS, 1994. Freshwater snails of Africa and their medical importance. Taylor and Francis, London.

Chingwena G, Mukaratirwa S, Chimbari M, Kristensen TK, Madsen H, 2011. Population dynamics and ecology of freshwater gastropods in the highveld and lowveld regions of Zimbabwe, with emphasis on schistosome andamphistome intermediate hosts. J Afr Zool 39, 55-62.

Colley DG, Bustinduy AL, Secor WE, King CH, 2014. Human schistosomiasis. Lancet 383, 2253-2264.

Folmer O, Black M, Hoeh W, Lutz R, Vrijenhoek R, 1994. DNA primers for amplification of mitochondrial cytochrome $\mathrm{c}$ oxidase subunit I from diverse metazoan invertebrates. Mol Mar Biol Biotechnol 3, 294-299.

Frandsen F, Christensen NO, 1984. An introductory guide to the identification of cercariae from African freshwater snails with special reference to cercariae of trematode species of medical and veterinary importance. Acta Trop 41, 181-202.

GeoHive, 2014. Chad population statistics. Avaliable at: http://www.geohive.com/cntry/chad.aspx (accessed on March 2014).

Guimarães RJPS, Freitas CC, Dutra LV, Felgueiras CA, Moura ACM, Amaral RS, Drummond SC, Scholte, RGC, Oliveira G, Carvalho OS, 2009. Spatial distribution of Biomphalaria mollusks at São Francisco River Basin, Minas Gerais, Brazil, using geostatistical procedures. Acta Trop 109, 181-186.

Kader AA, 2001. The effect of ecological parameters on the distribution of snail vectors of schistosomiasis. J Egypt Soc Parasitol 31, 145-152.

Kane RA, Stothard JR, Emery AM, Rollinson D, 2008. Molecular characterization of freshwater snails in the genus Bulinus: a role for barcodes? Parasit Vectors 1, 15.

Kariuki HC, Clennon JA, Brady MS, Kitron U, Sturrock RF, Ouma JH, Ndzovu STM, Mungai P, Hoffman O, Hamburger J, 2004. Distribution patterns and cercarial shedding of Bulinus nasutus and other snails in the Msambweni area, Coast province, Kenya. Am J Trop Med Hyg 70, 449-456.

Kazibwe F, Makanga B, Rubaire-Akiiki C, Ouma J, Kariuki C, Kabatereine NB, Booth M, Vennervald BJ, Sturrock RF, Stothard JR, 2006. Ecology of Biomphalaria (Gastropoda: Planorbidae) in Lake Albert, western Uganda: snail distributions, infection with schistosomes and temporal associations 
with environmental dynamics. Hydrobiologia 568, 433-444.

Kristensen TK, Malone JB, McCarroll JC, 2001. Use of satellite remote sensing and geographic information systems to model the distribution and abundance of snail intermediate hosts in Africa: a preliminary model for Biomphalaria pfeifferi in Ethiopia. Acta Trop 79, 73-78.

Labbo R, Djibrilla A, Zamanka H, Garba A, Chippaux JP, 2007. Bulinus forskalii: a new potential intermediate host for Schistosoma haematobium in Niger. Trans R Soc Trop Med Hyg 101, 847-848.

Labbo R, Ernould JC, Djibrilla A, Sidiki A, Chippaux JP, 2003. [Transmission of Schistosoma haematobium in the town of Niamey, Niger]. Bull Soc Pathol Exot 96, 178-182 (in French).

Mandahl-Barth G, 1962. Key to the identification of East and Central African freshwater snails of medical and veterinary importance. Bull World Health Organ 27, 135-150.

Massenet D, Abakar D, Karifene R, 1995. [Prevalence of urinary schistosomiasis in a school environment in N'Djamena (Chad)]. Bull Soc Pathol Exot 88, 35-37 (in French).

Moné H, Mouahid G, Morand S, 1999. The distribution of Schistosoma bovis Sonsino, 1876 in relation to intermediate host mollusc-parasite relationships. Adv Parasitol 44, 99-138.

Murray CJL, Vos T, Lozano R, Naghavi M, Flaxman AD, Michaud C, Ezzati M, Shibuya K, Salomon JA, Abdalla S et al., 2012. Disability-adjusted life years (DALYs) for 291 diseases and injuries in 21 regions, 1990-2010: a systematic analysis for the Global Burden of Disease Study 2010. Lancet 380, 2197-2223.

Ngonseu E, Greer GJ, Mimpfoundi R, 1992. [Population dynamics and infestation of Bulinus truncatus and Bulinus forskalii by schistosomal larvae in the Sudan-Sahelian zone of Cameroon]. Ann Soc Belg Med Trop 72, 311-320 (in French). Njiokou E, Onguen AR, Tchuem Tchuenté LA, Kenmogne A, 2004. [Urban schistosomiasis in Cameroon: a longitudinal study of its transmission in a new site of an extension of the intestinal schistosomiasis focus in Mélen, Yaoundé]. Bull Soc Pathol Exot 97, 37-40 (in French).

Owojori OJ, Asalou SO, Ofoezie IE, 2006. Ecology of freshwater snails in Opa Reservoir and research farm ponds at Obafemi Awolowo University Ile-Ife, Nigeria. J Appl Sci 6, 3004-3015.

Pedersen UB, Midzi N, Mduluza T, Soko W, Stensgaard AS, Vennervald BJ, Mukaratirwa S, Kristensen TK, 2014. Modelling spatial distribution of snails transmitting parasitic worms with importance to human and animal health and analysis of distributional changes in relation to climate. Geospat Health 8, 335-343.

Rollinson D, Knopp S, Levitz S, Stothard JR, Tchuem Tchuenté
LA, Garba A, Mohammed KA, Schur N, Person B, Colley DG et al., 2013. Time to set the agenda for schistosomiasis elimination. Acta Trop 128, 423-440.

Schur N, Hürlimann E, Garba A, Traoré MS, Ndir O, Ratard RC, Tchuem Tchuenté LA, Kristensen TK, Utzinger J, Vounatsou P, 2011. Geostatistical model-based estimates of schistosomiasis prevalence among individuals aged $\leq 20$ years in West Africa. PLoS Negl Trop Dis 5, e1194.

Simoonga C, Utzinger J, Brooker S, Vounatsou P, Appleton CC, Stensgaard AS, Olsen A, Kristensen TK, 2009. Remote sensing, geographical information system and spatial analysis for schistosomiasis epidemiology and ecology in Africa. Parasitology 136, 1683-1693.

Standley CJ, Vounatsou P, Gosoniu L, Jørgensen A, Adriko M, Lwambo NJS, Lange CN, Kabatereine NB, Stothard JR, 2012. The distribution of Biomphalaria (Gastropoda: Planorbidae) in Lake Victoria with ecological and spatial predictions using Bayesian modelling. Hydrobiologia 683, 249-264.

Steinauer ML, Mwangi IN, Maina GM, Kinuthia JM, Mutuku MW, Agola EL, Mungai B, Mkoji GM, Loker ES, 2008. Interactions between natural populations of human and rodent schistosomes in the Lake Victoria region of Kenya: a molecular epidemiological approach. PLoS Negl Trop Dis 2, e222.

Stensgaard AS, Utzinger J, Vounatsou P, Hürlimann E, Schur N, Saarnak CFL, Simoonga C, Mubita P, Kabatereine NB, Tchuem Tchuenté LA et al., 2013. Large-scale determinants of intestinal schistosomiasis and intermediate host snail distribution across Africa: does climate matter? Acta Trop 128, 378-390.

Utzinger J, Mayombana C, Mez K, Tanner M, 1997a. Evaluation of chemical and physical-morphological factors as potential determinants of Biomphalaria pfeifferi (Krauss, 1848) distribution. Mem Inst Oswaldo Cruz 92, 323-328.

Utzinger J, Mayombana C, Smith T, Tanner M, 1997b. Spatial microhabitat selection by Biomphalaria pfeifferi in a small perennial river in Tanzania. Hydrobiologia 356, 53-60.

Utzinger J, N'Goran EK, Caffrey CR, Keiser J, 2011. From innovation to application: social-ecological context, diagnostics, drugs and integrated control of schistosomiasis. Acta Trop 120, S121-S137.

Utzinger J, Tanner M, 2000. Microhabitat preferences of Biomphalaria pfeifferi and Lymnaea natalensis in a natural and a man-made habitat in southeastern Tanzania. Mem Inst Oswaldo Cruz 95, 287-294.

WHO, 2012. Accelerating work to overcome the global impact of neglected tropical diseases - a roadmap for implementation. Available at: http://whqlibdoc.who.int/hq/2012/WHO_HTM_ NTD_2012.1_eng.pdf?ua=1 (accessed on March 2014). 